\title{
15 Breaching the Sieve Element-The Role of Saliva as the Molecular Interface between Aphids and the Phloem
}

\author{
Torsten Will ${ }^{1}$, James C. Carolan ${ }^{2}$, and Thomas L. Wilkinson ${ }^{3}$ \\ ${ }^{1}$ Department of Applied Entomology, Justus-Liebig-University, Germany \\ ${ }^{2}$ Department of Biology, National University of Ireland Maynooth, Ireland \\ ${ }^{3}$ School of Biology and Environmental Science, University College Dublin, Ireland
}

Aphids (order Hemiptera; suborder Sternorrhyncha) are fast becoming an excellent system for studying molecular interactions between sap feeding insects and their host plants. This has been facilitated, in part, by the recent completion of the pea aphid (Acyrthosiphon pisum) genome project (IAGC, 2010) and the development of high throughput genomic resources such as preliminary genomes and large-scale EST libraries for a number of other aphid species. Coupled with a strong tradition as a model system for investigating insect-plant interactions more generally, the recent increase in the number of studies involving aphids has lead to greater insights into the complexity of plant-aphid interactions and has provided a tantalizing preview of the intricate molecular mechanisms that govern this intimate association.

Aphids and other sap-feeding hemipterans (e.g., whiteflies) have evolved specialized mouthparts, the stylets, which penetrate through plant tissues to feed directly from a single sieve element within the phloem. The feeding pathway, mechanism of penetration, and insect behavior associated with feeding have been well described (reviewed by Powell et al., 2006), but the role of the copious amounts of saliva that is continuously secreted during feeding remains obscure. Two types of saliva are recognized: a "gelling" saliva that constitutes the salivary sheath that is left in situ following stylet withdrawal from plant tissues, and a "watery" saliva that is secreted intracellularly either when the stylets briefly puncture cells during probing or immediately before and during sap ingestion (Martin et al., 1997). The gelling saliva is thought to provide mechanical support to the delicate stylets and to offer a degree of molecular concealment from plant defenses (Miles, 1999; Tjallingii, 2006; Will et al., 2007), although the assignment of function to the various types of saliva remains speculative, largely because of difficulties with collection and analysis of aphid saliva in general.

\footnotetext{
Abbreviations: ACE, angiotensin converting enzyme; Avr, avirulence; EPG, electrical penetration graph; GMC, glucosemethanol-choline oxidoreductase; NADH, nicotinamide adenine dinucleotide; NADPH, nicotinamide adenine dinucleotide phosphate; NBS-LRR, nucleotide-binding site leucine-rich repeat; PI, protease inhibitor; PAMPs, pathogen associated molecular patterns; PP1, phloem protein 1; PP2, phloem protein 2; PTI, PAMP-triggered immunity; Redox, reductionoxidation; RNAi, RNA interference; ROS, reactive oxygen species; SDS-PAGE, sodium dodecyl sulfate polyacrylamide gel electrophoresis; SMP-30, senescence marker protein
}

Phloem: Molecular Cell Biology, Systemic Communication, Biotic Interactions, First Edition.

Edited by Gary A. Thompson and Aart J.E. van Bel.

(C) 2013 John Wiley \& Sons, Inc. Published 2013 by John Wiley \& Sons, Inc. 
Nevertheless, several authors have suggested that aphid saliva mediates the insect-plant interaction by overcoming plant defenses before and after the sieve elements have been located (e.g., Miles, 1999; Tjallingii, 2006; Will et al., 2007). In contrast to the multitude of studies involving leaf-chewing insects (reviewed by Wu and Baldwin, 2010) direct evidence of a role for individual salivary proteins in the aphid-plant interaction is only slowly becoming available (Will et al., 2007; Mutti et al., 2008; Bos et al., 2010).

This chapter will discuss the potential role of aphid saliva within the sieve element, focusing largely on the watery saliva because this component is known to be actively secreted both prior to and during ingestion of phloem sap. However, it should be noted that the division of aphid saliva into gelling and watery components is based solely on physical properties, in particular the hardening of the saliva during tissue penetration that is not observed within the sieve element. Although protein profiles of the two types of saliva when analyzed by SDS-PAGE appear different (e.g., Cherqui and Tjallingii, 2000; Harmel et al., 2008) the protein composition of the different types of saliva has not been comprehensively compared, and the processes that govern the change in saliva conformation remain unknown.

\section{Aphid Saliva-Production, Secretion, and Composition}

The primary components of aphid saliva originate in the salivary glands, a pair of organs located in the dorsal metathorax (Ponsen, 1972). Each half of the salivary gland pair consists of two components, a large principal gland that is often bilobed and a smaller accessory gland. The two subunits join in a common duct that unites with the other partner to form the salivary canal that leads to the stylet tips. The principal gland is innervated and includes eight secretory cells, whereas the accessory gland has no nerve connections and the cells are not differentiated. The contribution of the two subunits to the saliva has been suggested largely through plant virus transmission studies (Gray and Gildow, 2003). Persistent and circulative viruses that infect the phloem are transferred from the aphid hemolymph into saliva through the accessory gland, indicating that this structure might be responsible for the production of some watery saliva. However, the relative contribution of the accessory and principal glands to saliva production remains unclear.

The salivary gland tissue of the pea aphid has recently been investigated in detail using transcriptomic and proteomic methodologies to generate a catalogue of putative effector proteins of the salivary secretome (Carolan et al., 2011). Effectors are generally defined as proteins and small molecules that alter host cell structure and function (Hogenhout et al., 2009). Over 300 proteins with secretion signals (N-terminal peptide sequences) indicating extracellular localization and possible association with saliva were identified from the salivary gland, approximately half of which had no homolog outside the aphids and were of unknown function. A significant number of the candidate effectors that could be assigned identity through homology were previously characterized in other phytopathogenic organisms, particularly plant-parasitic nematodes, perhaps indicating the evolution of common mechanisms to the plant-parasitic habit.

The composition of both the gelling and watery saliva has been investigated widely and is summarized in Table 15.1. Early studies primarily used enzymatic assays to determine protein activity of saliva and the salivary sheaths. The gelling process is thought to be mediated by an oxidation/reduction reaction involving phenoloxidases (Cherqui and Tjallingii, 2000; Tjallingii, 2006; Will et al., in press). In addition, phospholipids and conjugated carbohydrates have been detected in the sheath saliva (Miles, 1999). A candidate for the principal protein component of the sheath has been identified by mass spectrometry (Carolan et al., 2009). The amino acid composition 
Table 15.1 Proteins identified from or associated with aphid saliva

\begin{tabular}{|c|c|c|c|c|c|c|}
\hline Protein/enzyme type & Protein & $\begin{array}{l}\text { Method of } \\
\text { determination }\end{array}$ & Species & Fraction & Putative functions & References \\
\hline \multicolumn{7}{|l|}{ Glucosidases } \\
\hline & Cellulase & SSA & S. graminum & WO & Degrade cellulose & Campbell and Dreyer, 1990 \\
\hline & ND & SSA & S. graminum & Saliva & Degrade phenophilic glycosides & $\begin{array}{l}\text { Urbanska et al., 1994; } \\
\text { Cherqui and Tjallingii, } \\
2000\end{array}$ \\
\hline \multirow[t]{2}{*}{$\begin{array}{l}\text { GMC-oxidoreductase } \\
\text { family }\end{array}$} & Glucose dehydrogenase & MS, TP & A. pisum, M. persicae & Saliva, SGs & $\begin{array}{l}\text { Disrupt JA-regulated defense } \\
\text { responses, secondary metabolite } \\
\text { detoxification, salivary sheath } \\
\text { solidification }\end{array}$ & $\begin{array}{l}\text { Harmel et al., 2008; } \\
\text { Carolan et al., 2009, } 2011\end{array}$ \\
\hline & Glucose oxidase & SSA & M. persicae & Saliva & $\begin{array}{l}\text { Disrupt JA-regulated defense } \\
\text { responses, secondary metabolite } \\
\text { detoxification, salivary sheath } \\
\text { solidification }\end{array}$ & Harmel et al., 2008 \\
\hline $\begin{array}{l}\text { Olfactory segment } \\
\text { D2 family }\end{array}$ & Mp10 (OS-D2-like) & $\mathrm{TP}$ & M. persicae & SGs & $\begin{array}{l}\text { Chemosensory protein, potential } \\
\text { effector }\end{array}$ & Bos et al., 2010 \\
\hline $\begin{array}{l}\text { Pectinases and } \\
\text { pectinesterases }\end{array}$ & ND & SSA & S. graminum & Saliva & $\begin{array}{l}\text { Cell wall degradation during } \\
\text { probing and stylet penetration }\end{array}$ & $\begin{array}{l}\text { Ma et al., 1990; } \\
\text { Madhusudhan and Miles, } \\
\text { 1998; Cherqui and } \\
\text { Tjallingii, } 2000\end{array}$ \\
\hline $\begin{array}{l}\text { Polyphenoloxidases } \\
\& \text { peroxidases }\end{array}$ & ND & SSA & $\begin{array}{l}\text { S. graminum. S. avenae, } \\
\text { A. pisum, } M . \text { persicae }\end{array}$ & $\begin{array}{l}\text { Saliva, } \\
\text { Salivary } \\
\text { Sheath }\end{array}$ & $\begin{array}{l}\text { Phytochemical detoxification, } \\
\text { ROS scavenging to maintain } \\
\text { redox potential }\end{array}$ & $\begin{array}{l}\text { Urbanska et al., 1994; } \\
\text { Madhusudhan and Miles, } \\
\text { 1998; Miles and Peng, } \\
\text { 1988; Urbanska et al., } \\
\text { 1998; Cherqui and } \\
\text { Tjallingii, } 2000\end{array}$ \\
\hline
\end{tabular}


Table 15.1 (Continued)

\begin{tabular}{|c|c|c|c|c|c|c|}
\hline Protein/enzyme type & Protein & $\begin{array}{l}\text { Method of } \\
\text { determination }\end{array}$ & Species & Fraction & Putative functions & References \\
\hline Polygalacturonase & ND & SSA & A. pisum, M. persicae & Saliva & Cell wall degradation & Campbell and Dreyer, 1990 \\
\hline Metalloproteases & $\begin{array}{l}\text { M1 metalloprotease, } \\
\text { M2 metalloprotease }\end{array}$ & MS & A. pisum & Saliva, SGs & $\begin{array}{l}\text { Regulate or process signaling } \\
\text { peptides through cleavage of } \\
\text { di- or tri- peptides }\end{array}$ & Carolan et al., 2009 \\
\hline SMP-30 family & Regucalcin & MS & A. pisum & Saliva & $\begin{array}{l}\text { Calcium chelation, regulate sieve } \\
\text { element occlusion }\end{array}$ & Carolan et al., 2009 \\
\hline \multirow{6}{*}{$\begin{array}{l}\text { Proteins of unknown } \\
\text { function }\end{array}$} & Protein $\mathrm{C} 002$ & $\mathrm{TP}$ & A.pisum & SGs & Unknown function. & Mutti et al., 2006, 2008 \\
\hline & ACYPI009881 & MS, TP & A. pisum & Saliva, SGs & Component of the salivary sheath & Carolan et al., 2009, 2011 \\
\hline & ACYPI008224 & MS, TP & A. pisum & Saliva, SGs & Unknown function & Carolan et al., 2009, 2011 \\
\hline & ACYPI006346 & MS, TP & A. pisum & Saliva, SGs & Unknown function & Carolan et al., 2009, 2011 \\
\hline & $\begin{array}{l}40 \text { and } 43 \mathrm{kDa} \text { calcium } \\
\text { binding proteins }\end{array}$ & ${ }^{45} \mathrm{Ca}_{2}$ labeling & M. viciae & Saliva & $\begin{array}{l}\text { Calcium chelation, regulate sieve } \\
\text { element occlusion }\end{array}$ & Will et al., 2007 \\
\hline & $M p 42$ & $\mathrm{TP}$ & M. persicae & SGs & Potential effector & Bos et al., 2010 \\
\hline
\end{tabular}

ND: not determined; SSA: substrate specific assay; MS: mass spectrometry; TP; transcript profiling; SGs: salivary glands; WO: whole organism (homogenates). 
of this "sheath protein," a novel protein unique to aphids, suggests an abundance of disulfide bridges can form between cysteine residues consistent with a gelling function. Disulfide bridge formation is reversibly catalyzed by protein disulfide isomerases and several disulfide isomerases were identified in the pea aphid salivary gland secretome (Carolan et al., 2011). Watery saliva appears to have a more complex composition. Substrate-specific assays have demonstrated the presence of two pectinases, pectin methylesterase, polygalacturonase, and oxidation/reduction enzymes such as phenoloxidases and peroxidases (Urbanska et al., 1998; Madhusudhan and Miles, 1998; Miles, 1999). More recently, mass spectrometry and proteomics of aphid salivary proteins secreted into artificial diets identified metalloproteases, glucose dehydrogenases and oxidases, regucalcin, NADH dehydrogenase, and several novel proteins with no homolog outside aphids (Harmel et al., 2008; Carolan et al., 2009).

In addition to structural and enzymatic functions, novel molecular roles for constituents of aphid saliva are being recognized. For example, it is becoming increasingly evident that a gene-for-gene interaction exists between the aphid and its plant host, analogous to the interactions that occur between plants and phytopathogens such as nematodes, oomycetes, fungi, and bacteria. As with these phytopathogenic organisms, it is expected that aphids secrete analogous pathogen-associated molecular patterns (PAMPs) that are recognized by the plant, and subsequently salivary effectors that in some way negate the response to such recognition. Recent functional genomic (Bos et al., 2010) and RNA library prospecting (Mutti et al., 2006, 2008) approaches have yielded candidate proteins (Table 15.1) that could potentially function at the molecular interface between aphid and plant.

Calcium chelating proteins have also been demonstrated in aphid saliva through calcium affinity studies (Will et al., 2007) and mass spectrometry of proteins isolated from concentrated saliva (Carolan et al., 2009). The presence of such proteins might explain the ability of aphids to contend with calcium-regulated sieve element occlusion mechanisms and calcium-based defense signaling pathways. Thus, it seems that aphid saliva is diverse both in protein composition and function.

\section{Stylet Penetration toward the Sieve Elements: The Role of the Salivary Sheath}

The route taken by the stylets as they penetrate plant tissues has been reconstructed from serial sections of salivary sheaths viewed by both light and electron microscopy (Tjallingii and Esch, 1993). After initially secreting a salivary "flange" on the plant surface, the stylet tips penetrate between cells and through airspaces and briefly puncture individual cells as they progress to the sieve elements. The route can be circuitous, commonly involving dead-ends, direction reversal, and aborted sieve-element punctures. Overall, it can take from 30 minutes to several hours for the aphid to locate a suitable feeding site. Analysis by electrical penetration graph (EPG) (Mclean and Kinsey, 1965; Prado and Tjallingii, 1994; Walker, 2000), a technique to observe aphid behavior during plant probing and ingestion, has added considerable detail to these directly unobservable events (see Chapter 16). Often the frequency of cell punctures increases immediately before the final feeding site is attained, and salivary secretions seem to be important in the decision of the insect to accept or reject a sieve element that could be mediated by gustatory receptors in the pharynx (Hewer et al., 2010). However, the cell puncture that leads to sustained phloem ingestion appears indistinguishable from other previous cell punctures.

The puncturing of plant cells, either in the mesophyll or the sieve elements, presents aphids with a serious problem since loss of internal turgor pressure and the influx of calcium ions results in the initiation of defensive cascades that could interrupt feeding behavior. In this regard, the salivary sheath plays an important role since it can effectively seal puncture sites irrespective of the plant 
cell type. Nevertheless, the continuous secretion of gelling saliva during penetration to the sieve element presents a considerable input of "foreign" material into the plant that has the potential to activate plant defense responses. Early reports in the literature suggested that the gelling saliva contained enzymes such as pectinases and cellulases that are capable of digesting plant cell walls to aid penetration (Table 15.1). Although the stylets predominantly follow the secondary cell walls and thus encounter cellulose fibers (Tjallingii and Esch, 1993) and a pectin layer, it has yet to be determined whether the products of their digestion (pectin fragments for example) act as elicitors of plant defense (Cherqui and Tjallingii, 2000). Obviously, teasing apart the seemingly conflicting roles of cell wall digesting enzymes present in aphid saliva requires considerably more attention.

\section{Penetration of the Sieve Element: The Role of Watery Saliva}

Upon puncturing the sieve element, the aphid initiates a period of sieve-element salivation that involves the injection of watery saliva directly into the sieve element lumen (Tjallingii, 2006). Secretion of saliva coincides with the closing of the precibarial valve in the food canal in the aphid head, so that saliva remains in the mouthparts rather than being drawn through the stylet and into the gut as occurs during ingestion (Figure 15.1). It is assumed that saliva is secreted into the lumen of the sieve element and transported within the sieve tube by mass flow. It is unclear how far the stylet tip progresses into the sieve element and it is feasible that saliva could accumulate in the stationary mictoplasm at the inner periphery of the sieve element. However, early experiments with ${ }^{32} \mathrm{P}$-labeled aphids detected radioactivity in unlabeled aphids (and plant roots) downstream of the feeding site, indicating that saliva enters the sieve element lumen and is carried with the mass flow within sieve tubes (Forrest and Noordink, 1971). The secretion of watery saliva prior to ingestion has long been considered a significant factor in the conditioning of the sieve element prior to ingestion. Such conditioning most likely involves secretion of effector molecules to overcome or negate plant defenses such as protein occlusion mechanisms, although the identification of such effectors is still at an early stage (Bos et al., 2010). Irregularities in sieve element salivation have been observed in aphids feeding from resistant plant cultivars (van Helden and Tjallingii, 1993; Garzo et al., 2002; Alvarez et al., 2006; Tjallingii, 2006) and in aphids experimentally deprived of an endogenous supply of essential amino acids through elimination of their bacterial endosymbionts (Wilkinson and Douglas, 1995). In both cases, incompatibilities between the sieve element and protein composition of the saliva are thought to underlie the irregular feeding behavior exhibited by the aphids.

To initiate ingestion, the precibarial valve opens and the aphid imbibes sieve-tube sap passively due to the positive pressure associated with mass flow. The opening of the salivary canal is situated just behind the tip of the stylets (Figure 15.1) such that once ingestion starts, saliva is swept back into the aphid with the stream of sieve-tube sap (e.g., Tjallingii, 2006). The functional implications for the ingestion of saliva are unclear, but one likely explanation involves prevention of protein plug formation in the narrow food canal or aphid gut. The intermittent secretion of watery saliva is critical for sustained feeding, and the precibarial valve will close periodically to allow the emission of watery saliva back into the sieve element. Severing of aphid stylets by stylectomy (Fisher and Frame, 1984; van Helden et al., 1994) during ingestion interrupts the secretion of watery saliva into the sieve element and in eudicots, sieve-tube sap eventually ceases to flow presumably due to the plugging of the stylet tips or sieve element. It is clear that saliva plays a major role in the interaction between the aphid and the sieve-tube from which it feeds. 
(A) Sieve element salivation

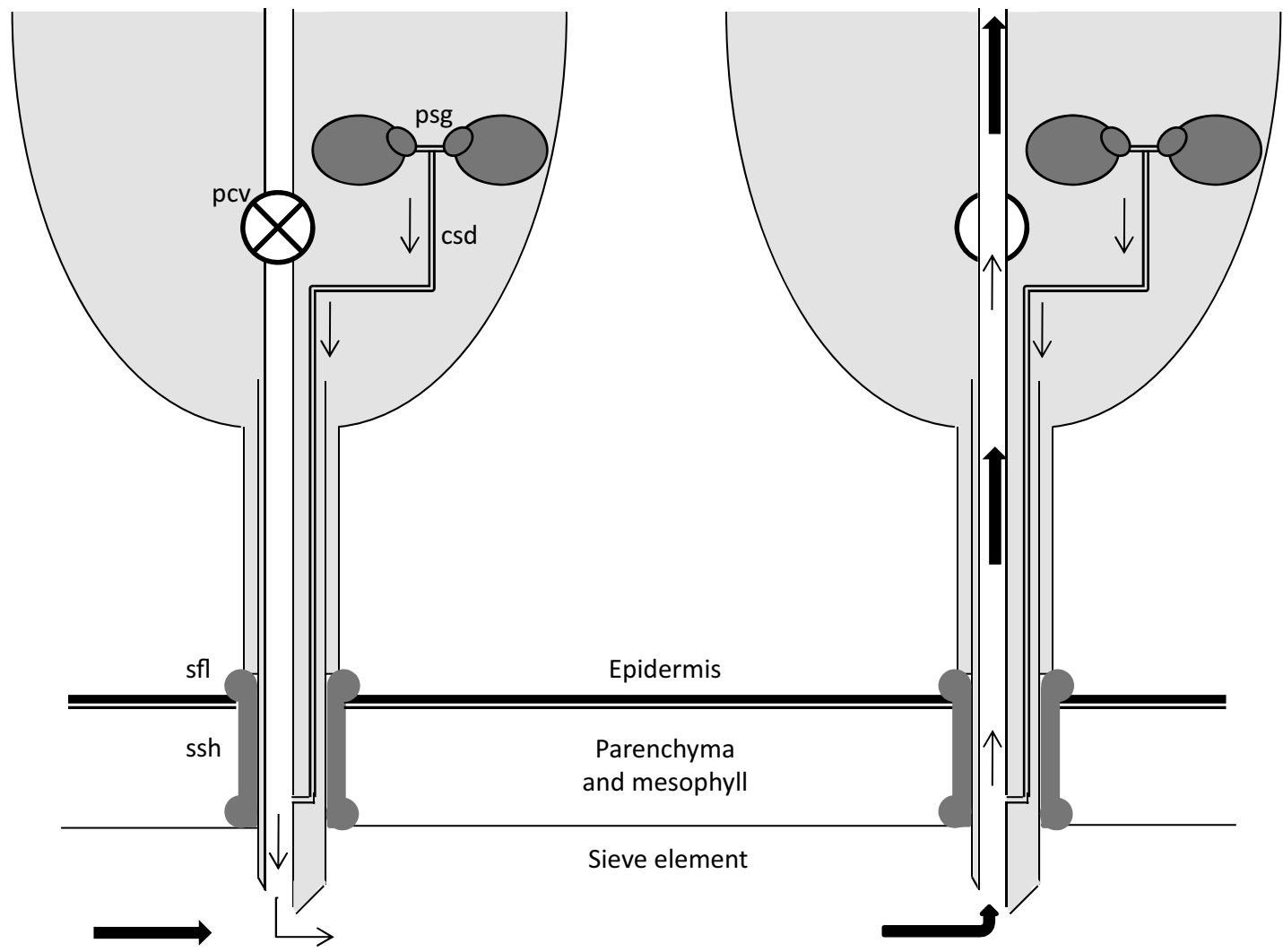

Figure 15.1 Schematic representation of the movement of saliva and sieve-tube sap during sieve element salivation and passive phloem ingestion. (A) Sieve element salivation originates from saliva in the paired salivary glands (psg; each comprising a principal and accessory gland) that is continually secreted via the common salivary duct (csd) from an opening in the stylet bundle distal to the tip. During penetration of pathway tissues to the sieve element the saliva hardens to form an initial salivary flange (sfl) and salivary sheath (ssh) surrounding the stylets. During penetration and brief intracellular punctures as well as initially entering the sieve element, the precibarial valve (pcv) in the head remains closed and saliva exits from the tip of the stylet bundle. (B) Passive phloem ingestion occurs if the stylet-sieve element interaction is compatible. The precibarial valve opens and sieve-tube sap together with secreted saliva is imbibed passively due to the positive pressure in the sieve element. Small arrows indicate the direction of saliva flow; large arrows indicate the direction of sieve tube sap flow.

\section{Aphids Manipulate Sieve Element Occlusion}

\section{Sieve Element Occlusion Mechanisms}

Sieve elements are particularly sensitive to injury and under extreme conditions will completely collapse. More commonly, mechanical damage or feeding damage by herbivores leads to a blockage or occlusion of the sieve elements to prevent leakage of the sieve tube contents (see Chapter 7). Occlusion mechanisms can act relatively slowly (minute range) in case of callose deposition or rapidly (second range) by plugging with proteins (Furch et al., 2007, 2010). Both occlusion 
mechanisms can act concurrently to effectively block mass flow through sieve pores between adjacent phloem cells (see Chapter 7). Callose, a 1,3- $\beta$-glucan polymer (Aspinall and Kessler, 1957), is synthesized in the cell wall outside the plasma membrane by the enzyme callose synthase, which is activated by increased levels of intracellular calcium. Because of the site of synthesis, callose plugs are actually more like collars that constrict the sieve pores.

Protein-based sieve pore occlusion mechanisms can occur more rapidly and involve a wide variety of putative protein structures (Evert, 1990). The types of protein plugging mechanisms that are present depend upon the plant family but all mechanisms lead to blockage of the sieve plate by formation of a plug. Sieve elements of plants in the Fabaceae contain forisomes, which are unique protein structures with a spindle-like appearance that disperse in response to fluctuations in turgor pressure or damage (Knoblauch et al., 2001). These physical changes to sieve elements also lead to increased levels of intracellular calcium. Isolated forisomes in vitro can be induced to disperse by the addition of calcium and contract by the addition of calcium chelators (Knoblauch et al., 2003) or crude extracts of concentrated aphid saliva (Will et al., 2007). This rapid structural conversion of forisomes suggests that an unidentified component of aphid saliva plays a vital role in mitigating defense responses in this particular plant family.

\section{How Aphids React to Sieve Element Occlusion}

Secretion of watery saliva into sieve elements directly after penetration by the aphid stylets, but prior to sieve-tube sap ingestion is a common behavior that has been observed for all aphid species studied to date. Furthermore, detailed analysis of aphid feeding behavior has demonstrated that aphids respond to artificial induction of sieve element occlusion with prolonged periods of watery saliva secretion (Will et al., 2007, 2009). This observation was made for a number of different aphid species on highly divergent plant taxa, suggesting that salivation into sieve tubes is a general mechanism to suppress sieve element occlusion (Will et al., 2009).

Factors that can trigger the previously described occlusion mechanisms include calcium fluxes (Knoblauch et al., 2001), turgor loss (Ehlers et al., 2000), and variations in redox potential (Leineweber et al., 2000).

\section{Occlusion Associated Factors: Calcium}

Calcium plays a central role in the induction of sieve element occlusion, either as a trigger for a variety of mechanisms (Furch et al., 2007) or as a second messenger in defense-associated signal cascades (Lecourieux et al., 2006), leading to the hypothesis that proteins within the watery saliva limit or modulate calcium influx (Will and van Bel, 2006). Such proteins appear to be a key factor in the ability of aphids to imbibe phloem sap by preventing sieve element occlusion (Caillaud and Niemeyer, 1996; Chen et al., 1997). Whether aphids prevent occlusion of sieve elements as opposed to directly disintegrating the protein and callose plugs is as yet undetermined.

\section{Occlusion Associated Factors: Hydrostatic Pressure}

Mass flow inside the sieve tubes is driven by a hydrostatic pressure difference between source and sink (Münch, 1930; Gould et al., 2005). The high turgor pressure of sieve tubes results in passive ingestion of sieve-tube sap (Prado and Tjallingii, 1994; Tjallingii and Cherqui, 1999; Miles, 1999), and the flow of ingesta is regulated by the preciberial valve that opens and closes the food canal 
(McLean and Kinsey, 1984). Loss of turgor in sieve tubes would therefore lead to a reduction in the rate of ingestion or cessation of feeding altogether.

Sieve tube occlusion leads to a decrease of pressure downstream of the occlusion-inducing stiumulus (Gould et al., 2004) and a reduction in flow velocity inside the sieve tubes (Peuke et al., 2006). Using a flow chamber system in which a single aphid penetrates a stretched parafilm membrane with its stylet and feeds on artificial diet, it was demonstrated that aphid behavior changes from ingestion to secretion of watery saliva after a rapid decrease of system pressure (Will et al., 2008), while an increase of calcium had no effect. This suggests that aphids respond to a drop in hydrostatic pressure following sieve element occlusion rather than calcium influx (Will et al., 2008).

\section{Occlusion Associated Factors: Redox State}

The redox state represents the sum of the reducing and oxidizing potentials of the molecules in plant cells (Potters et al., 2010) and is involved in plant stress biology and pathogen responses (Foyer and Noctor, 2005). In addition to calcium, the redox state inside sieve tubes represents a further trigger factor for protein based occlusion mechanisms in cucurbits. Solubilized phloem protein monomers (PP1) together with phloem lectin (PP2) form filaments due to oxidation (Read and Northcote, 1983; Leineweber et al., 2000) leading to sieve-tube occlusion. Furthermore variation of the redox state has been implicated in conferring disease resistance in plants (Van Camp et al., 1998).

The redox state of a cell is influenced by phenolic compounds and antioxidants, such as ascorbate, glutathione, and NADH/NADPH (Queval and Noctor, 2007; Potters et al., 2010). Reactive oxygen species (ROS) are toxic byproducts of aerobic metabolism, which in addition to contributing to cellular redox state (Potters et al., 2010) can adversely affect plant cell health leading to programmed cell death (de Pinto et al., 2002). ROS are suspected to play an integrative role in aphid-plant interactions. For example, sieve element feeding by aphids results in the production of the ROS hydrogen peroxide in the apoplast of aphid resistant plants (van der Westhuizen et al., 1998), indicating that aphids directly induce or trigger plant defenses under certain circumstances. Thus, aphids are confronted with antioxidant-based defense systems localized in the sieve tubes (Walz et al., 2002). It is likely that aphids and other phytophagous insects secrete a suite of scavenging proteins that contend with the ROS associated with biotic attack or cellular damage.

One potential strategy aphids can use to influence ROS levels in the plant is to secrete oxidoreductase enzymes in the saliva. Many oxidoreductases have been identified in or are associated with saliva from different aphid species (reviewed by Miles, 1999). This group of enzymes include copper-dependent oxidoreductases (Madhusudhan and Miles, 1998), phenoloxidases (Cherqui and Tjallingii, 2000; Ma et al., 2010), glucose oxidase (Harmel et al., 2008), glucose dehydrogenase (Carolan et al., 2009) and peroxidase (Urbanska et al., 1998; Cherqui and Tjallingii, 2000).

With respect to ROS scavenging the identification of glucose-methanol-choline (GMC) oxidoreductases in the saliva of the pea aphid and green peach aphid (Harmel et al., 2008; Carolan et al., 2009) is particularly contradictory, as GMC-oxidoreductases convert glucose, a component of sieve element sap (van Bel and Hess, 2008) to gluconic acid and hydrogen peroxide both of which are ROS. Therefore, salivary enzymes may actually result in an increase in ROS content.

Besides functioning in plant defense responses, ROS are increasingly implicated as key signaling molecules involved in cell-to-cell communication (reviewed by Suzuki et al., 2012). It is therefore not unreasonable to assume that aphid modulation of ROS and ROS scavengers could confer an ability to control ROS-based signaling pathways. 


\section{Suppression of Sieve Element Occlusion by Calcium-Binding Saliva Components}

An in vitro approach to investigate whether components of aphid watery saliva suppress sieve element occlusion mechanisms was conducted using isolated forisomes from broad bean (Vicia faba) and concentrated aphid saliva from the vetch aphid (Megoura viciae). In translocating sieve elements of Fabaceae, forisomes exist in a contracted spindle-like shape that permits free mass flow through the sieve element lumen. Physical disruption or membrane depolarization of sieve elements (effected by electropotential waves) result in a calcium influx that induces forisome transition from the fusiform into a larger, dispersed globular conformation that prohibits mass flow through sieveplate occlusion (Knoblauch and van Bel, 1998). Aphid saliva changes forisomes from their dispersed state back into their contracted state. The absence of forisome transformation in the presence of proteolytically digested salivary proteins indicates an active role for salivary proteins in sequestering calcium to prevent occlusion. Seven proteins of different molecular weights with putative roles in calcium binding were obtained from watery saliva collected from several thousand individuals of the vetch aphid feeding from artificial diets (Will et al., 2007). Large volumes of artificial diets were also used for the mass spectrometry-based identification of other putative calcium-binding candidates (Carolan et al., 2009).

\section{Stabilization of Sieve Element Calcium-Homeostasis by a Secreted Regucalcin-Like Protein?}

Proteomic characterization of secreted saliva from pea aphids identified a regucalcin-like protein, a candidate calcium-binding protein (Carolan et al., 2009). This salivary protein has a molecular mass of $43 \mathrm{kDa}$, which is comparable in size to a calcium-binding protein that was previously detected in aphid saliva (Will et al., 2007). Regucalcin is a member of the senescence marker protein-30 (SMP-30) family that functions by sequestering signaling molecules such as calcium (Fujita et al., 1992; Shimokawa and Yamaguchi, 1993). In addition, regucalcin plays a pivotal role in maintaining intracellular calcium homeostasis by activating calcium-pumps in the plasma membrane, endoplasmic reticulum, and mitochondria of many animal cell types (Yamaguchi, 2000). Moreover, regucalcin has an inhibitory effect on the activation of calcium/calmodulin-dependent enzymes and protein kinase $\mathrm{C}$ and has been demonstrated to regulate nuclear function in liver cells through the inhibition of calcium-activated DNA fragmentation, DNA and RNA synthesis, protein kinase, and protein phosphatase activities in the nuclei (Yamaguchi, 2005). However, since sieve elements do not possess nuclei, the secreted regucalcin might not be particularly relevant for DNAand RNA-associated functions. Plant homologs of the SMP-30 protein have not been described so far, which adds to the mystery of how aphid SMP-30 proteins function. However, it is evident from the ever-expanding list of aphid saliva proteins that a specific function within the aphid does not necessarily equate to the same function when secreted into the plant (Carolan et al., 2011).

\section{Salivary Proteins: Modifiers of Ingestion and the Sieve Element Environment}

\section{The C002 Salivary Protein Is a Relevant Effector for Ingestion}

C002, a salivary protein localized to the principal salivary glands of pea aphid, plays a significant role in successful aphid feeding (Mutti et al., 2008). Suppression of C002 transcripts by RNA interference (RNAi) in pea aphids led to a reduction in aphid life span and the ability of the aphid to locate or 
reach the sieve elements during probing (Mutti et al., 2006). In the few successful penetrations to the sieve element, the aphids were unable to sustain sieve-tube sap ingestion for longer than 30 minutes (Mutti et al., 2008). The fecundity of the green peach aphid (Myzus persicae) increased when reared on Nicotiana benthamiana with ectopically expressed C002, suggesting that the protein functions as an effector that is integral to promoting aphid infestation (Bos et al., 2010). Interestingly, pea aphid and green peach aphid C002 are divergent in amino acid sequence (Mutti et al., 2006; Bos et al., 2010), but no biological significance for the divergence has as yet been attributed.

\section{Influence of Salivary Proteins on Ingested Sieve-Tube Sap Content}

At the onset of ingestion, secreted saliva is drawn into the gut with the flow of sieve-tube sap (Figure 15.1). Prevention of sieve-element protein coagulation in the digestive track by calciumbinding is most likely one important function of saliva to prevent occlusion of the narrow food canal of the stylet (Tjallingii, 2006). The presence of specialized cells that accumulate calcium in the form of calcium sulfate and calcium carbonate in the midgut (Ehrhardt, 1965) could indicate that reingested calcium binding salivary proteins are less relevant. Ingested saliva could also function to detoxify sieve-tube sap components that are harmful to aphids including protease inhibitors (PIs), which are known constituents of the sieve-tube sap. Sieve tube PIs could potentially target proteases within the insect midgut and thus, prevent digestion of nutritive proteins and consequently restrict insect growth and development by limiting nitrogen supply. Cysteine and trypsin PIs have been shown to reduce aphid performance (Casaretto and Corcuera, 1998; Rahbé et al., 2003; Pyati et al., 2011), but the response is often species-specific, and in some host plants, accumulation of the PI is induced by aphid infestation.

A long-held assumption argues against a role for PIs in the gut because of the belief that aphids were incapable of digesting protein, relying instead on free amino acids in the sieve-tube sap as the primary source of nitrogen-based nutrition (e.g., Sandstrom, 2000). However, active proteases have been found in the midgut of the pea aphid (Cristofoletti et al., 2006), and two proteases were identified in pea aphid saliva (Carolan et al., 2009). Taken together with evidence of PI activity against a variety of aphid species, some proteolytic activity must be present in the aphid gut (Pyati et al., 2011). Plant PIs could potentially cross the midgut epithelium into the hemolymph and negatively influence aphid metabolism or processes related to reproduction (Rhabé et al., 2003).

The two proteases identified in the saliva of the pea aphid are a M1 zinc metalloprotease and angiotensin converting enzyme-like enzyme (ACE-like), which is a member of the M2 metalloprotease family (Carolan et al., 2009). The ACE homolog was previously described in insect hemolymph, but its association with saliva and the salivary glands has recently been confirmed (Carolan et al., 2011). Both M1 and M2 zinc metalloproteases are involved in the digestion of small peptides and similar proteases are present in the saliva of other fluid-feeding insects such as mosquitoes (Arca et al., 2005) and ticks (Decrem et al., 2008). In addition to a putative role in the digestion of proteins within the sieve elements (Carolan et al., 2009), these salivary metalloproteases could also function within the insect gut to deactivate plant PIs in the diet. M1 and M2 metalloproteases cleave one or two amino acids from the $\mathrm{C}$ - and $\mathrm{N}$-terminal ends, respectively, from short peptides such as hormones or neuropeptides indicating a potentially direct role in negating or modulating various defensive signaling mechanisms.

Phytochemicals in the ingested sieve element sap such as phenolic compounds would have to be detoxified by the aphid either in the plant or in the aphid midgut. This could be achieved by oxidoreductases (Miles and Oertli, 1993) such as those identified in the saliva of green peach 
aphid and pea aphid (Harmel et al., 2008; Carolan et al., 2009). Salivary GMC-oxidoreductases could fulfill a potential function within the aphid if reingested. However, further identification and characterization of the salivary components along with functional assays are clearly necessary before the role of salivary proteins in pre- and postingestion events is fully understood.

\section{Potential Recognition of Salivary Proteins by Intracellular Receptors}

There is a growing appreciation that the relationship between sap-feeders and their host plants is much more intricate than the relatively indiscriminate feeding of many polyphagous-chewing insects. The mouthparts of an aphid locate and penetrate a single sieve element from which they can feed for days, often without causing significant damage to the plant. By doing so, aphids and whiteflies induce plant defense signaling pathways that are also activated by bacterial or fungal pathogens (de Vos et al., 2005; Kempema et al., 2007), indicating remarkable functional analogy among these phylogenetically diverse phytopathogenic organisms (Walling, 2000; Goggin, 2007). As discussed in Chapter 16, the only cloned aphid resistance genes, Mi-1.2 in tomato (Solanum lycopersicum) (Martinez de Ilarduya et al., 2003) and Vat in melon (Cucumis melo) (Dogimont et al., 2008), are members of the NBS-LRR superfamily of resistance proteins that confer resistance to both eukaryotic and prokaryotic pathogens (Staal and Dixelius, 2007). As with the secretions of other plant pathogens, aphid saliva most likely comprises pathogen-associated molecular patterns (PAMPs) and proteins that result in plant-derived products that are analogous to pathogen-induced molecular patterns. Whether or not the plant mounts a successful defense, resulting in pathogentriggered immunity (PTI), for example, depends on the presence of additional salivary agents such as avirulence (Avr) gene products that function as effectors that essentially interfere with PTI.

Recent results suggest that the expression of $M i-1.2$ and VAT is not restricted to sieve elements (Sarria-Villada et al., 2009; Pallipparambil et al., 2010) and, since both gene products are located in the cytoplasm in common with most plant NBS-LRR proteins (McHale et al., 2006), plants are likely to recognize aphid infestation at an early stage of probing before sieve element penetration. A potential candidate protein that is detected by the plant is MP42 from the saliva of green peach aphid, whose overexpression in Nicotiana benthamiana leads to reduction in aphid performance, indicating an induced defense response against aphids (Bos et al., 2010).

Microscopic hypersensitive-like responses have been observed in mesophyll tissues of melon plants possessing the VAT gene in response to cotton-melon aphid (Aphis gossypii) probing (SarriaVillada et al., 2009). In contrast, a hypersensitive response was absent in tomatoes with the $M i-1.2$ gene (Martinez de Ilarduya et al., 2003), suggesting that alternative defense mechanisms are mediated by NBS-LRR proteins. Interestingly, the microscopic hypersensitive-like responses in melon plants that express VAT is a rapidly induced host response when probed by cotton-melon aphids whereas a significant temporal lag of similar responses occurs after green peach aphid probing (i.e., a nonhost response). It is not unreasonable to postulate that the rapid response is based upon a direct detection of an Avr gene product in cotton-melon aphid saliva while the delayed response can be assigned to innate immunity.

\section{Salivary Proteins Influence Metabolic Pathways in the Phloem}

Aphid feeding changes resource allocation within the host plant by altering sink-source relationships (Girousse et al., 2003). Nutrients are suggested to be preferentially allocated toward insect-infested 
tissue due to the creation of strong sinks as sieve-tube sap is ingested by the aphids (Girousse et al., 2003). The demand for nutrients in response to a dense infestation of aphids imposes such a strongly competitive sink that normal sink tissues such as primary growth zones have been suggested to convert to source tissues (Mittler and Sylvester, 1961; Dixon, 1998; Girousse et al., 2005). This assumption is questionable because of the need for substantial structural changes involved in a switch from sink to source tissues.

Aphid feeding can also alter the biochemical composition of sieve-tube sap to enhance the nutritional quality of the aphid's diet. Infestation of wheat (Triticum aestivum) by greenbug (Schizaphis graminum) and Russian wheat aphid (Diuraphis noxia), induced an increase in both total amino acid content and the relative amount of essential amino acids in the sieve element sap (Sandstrom, 2000). The increased amino acid content could be caused by degradation of sieve element sap proteins due to secreted salivary proteases. Similar results were obtained following feeding by the bird cherry-oat aphid (Rhopalosiphum padi) on maize (Zea mays) and barley (Hordeum vulgare) (Eleftherianos et al., 2006), but in this study there was no effect on the amino acid composition in response to feeding by greenbugs.

Systemic activation of metabolic genes was observed in the phloem of celery (Apium graveolens) in response to feeding by green peach aphid (Divol et al., 2005). In contrast, premature leaf senescence in Arabidopsis following feeding by green peach aphid is thought to be a resistance mechanism that limits aphid growth by exporting nutrients from the leaf (Pegadaraju et al., 2005). Irrespective of the final outcome, it seems clear that aphid feeding can alter phloem biochemistry to influence aphid fitness. The involvement of aphid salivary proteins in this process remains speculative, but the secretion of saliva into the sieve element represents a plausible recognition mechanism. However, the plant receptors and signaling mechanisms that ultimately determine phloem composition remain obscure.

\section{Future Directions}

The continued identification and characterization of aphid salivary proteins is central to understanding interactions between sapfeeding insects and their host plants. The availability of the pea aphid genome and the imminent completion of genomic projects for other aphid species will result in a greater level of insight into these interactions at the molecular level. The continued collaborative efforts of the IAGC and the dedicated curation of aphid bioinformatic resources have resulted in the availability of extensive genomic resources and databases to the wider scientific community. In addition, methods such as next generation sequencing to investigate the aphid transcriptome, in planta expression of aphid salivary proteins, RNA interference, and mass spectrometry-based proteomics are all contributing to a greater understanding of the composition and function of aphid salivary proteins.

The continued identification of salivary proteins will lead to two main areas of research. The first of these will involve assessing the variability within the salivary proteome itself. For example, it is unknown whether there are differences between the principal and accessory gland proteome or whether the watery and gelling saliva differ in protein composition. Wide-scale interspecific and intraspecific comparisons are required to determine the effect of host plant and phylogeny on the salivary proteome. Such studies will involve investigating salivary proteome variability among specialist and generalist aphid species or monocot and eudicot feeders, leading to a better understanding of the evolution of the plant-aphid interaction. It is also important that attempts are made to attribute the different levels of plant resistance or susceptibility and aphid virulence 
or avirulence to variability within the salivary proteome or within the individual salivary proteins themselves.

Although proteomic, functional genomic, and comparative pathogenomic approaches will result in the generation of lists of candidate proteins involved in the various levels of the plant-aphid interaction, considerably more effort will be required to deduce their actual function within the plant. This second and probably most important area of research will employ methods such as in planta expression of salivary proteins or other salivary protein delivery methods to determine changes in the plant proteome and transcriptome, in the levels of susceptibility and resistance, and in plant physiological responses such as hypersensitive response or chlorosis. The functional characterization of individual salivary proteins will benefit from the continued use of plant nearisogenic lines and plant cultivars (some of which are transgenic) that demonstrate a given phenotype in response to specific functional activities of the foreign protein under study. For many of the plant cultivars used in reporter bioassay experiments, the molecular pathways and cascades that result in a given phenotype are known and thus, the potential to couch the plant-aphid salivary protein interaction in molecular terms is achievable.

Finally, in addition to the continued characterization of the plant-aphid interaction at the molecular level, it is essential that the tradition of excellent plant physiology experiments involving aphids continue. For example, additional in vivo and in vitro sieve element occlusion experiments are required to further characterize the events that occur within the sieve element itself. Stalwart methods such as the remarkably illuminating EPG technique and aphid stylectomy will undoubtedly remain integral to understanding the mechanisms of feeding before and after the sieve element is located. Future studies intent at measuring changes in plant cell microenvironment in response to aphid feeding or stylet penetration have been used in the past but require significantly more attention. Such experiments measure $\mathrm{pH}$, ROS, and calcium levels of individual cells and tissues before and after aphid feeding and will yield insights into the plant-aphid interaction at the cellular and biochemical levels. Immunodetection studies using antibodies obtained for individual salivary proteins will validate the in planta delivery of salivary proteins and can potentially be used to visualize salivary proteins at the cellular level. And finally plant microscopy will continue to provide the direct observation of physical interaction between the stylets (and salivary sheath) and the cells and sieve elements they encounter during the feeding process.

In conclusion, the mechanistic role of individual salivary proteins in processes such as calcium chelation, ROS modulation, structural modification, nutrient enhancement, phytochemical detoxification, avirulence, effector, and PAMP functions is slowly emerging. The postgenomic era for aphids and many of the plants on which they feed is encouraging renewed interest in aphid-plant interactions and will undoubtedly lead to a deeper understanding of this intimate and fascinating relationship.

\section{References}

Alvarez AE, Tjallingii WF, Garzo E, Vleeshouwers V, Dicke M, Vosman B (2006) Location of resistance factors in the leaves of potato and wild tuber-bearing Solanum species to the aphid Myzus persicae. Entomol Exp Appl 121: 145-157.

Arca B, Lombardo F, Nolan T, Lycett G, Lanfrancotti A, Stich N, Catteruccia F, Louis C, Coluzzi M (2005) An Anopheles gambiae salivary gland promoter analysis in Drosophila melanogaster and Anopheles stephensi. Insect Mol Biol 14: 207-216.

Aspinall GO, Kessler G (1957) The structure of callose from the grape vine. J Soc Chem Ind 39: 1296.

Bos JIB, Prince D, Pitino M, Maffei ME, Win J, Hogenhout SA (2010) A functional genomics approach identifies candidate effectors from the aphid species Myzus persicae (Green Peach Aphid). PLoS Genet 6: e1001216. 
Caillaud CM, Niemeyer HM (1996) Possible involvement of the phloem sealing system in the acceptance of a plant as host by an aphid. Experientia 52: 927-931.

Campbell DC, Dreyer DL (1990) The role of plant matrix polysaccharides in aphid-plant interactions. In Campbell RK, Eikenbary RD, eds, Aphid-Plant Genotype Interactions. Elsevier, Amsterdam, The Netherlands, pp 149-170.

Carolan JC, Caragea D, Reardon KT, Mutti NS, Dittmer N, Pappan K, Cui F, Castaneto M, Poulain J, Dossat C, et al. (2011) Predicted effector molecules in the salivary secretome of the pea aphid (Acyrthosiphon pisum): a dual transcriptomic/proteomic approach. J Proteome Res 10: 1505-1518.

Carolan JC, Fitzroy CIJ, Ashton PD, Douglas AE, Wilkinson TL (2009) The secreted salivary proteome of the pea aphid Acyrthosiphon pisum characterised by mass spectrometry. Proteomics 9: 2457-2467.

Casaretto JA, Corcuera LJ (1998) Proteinase inhibitor accumulation in aphid-infested barley leaves. Phytochemistry 49: $2279-2286$.

Chen JQ, Rahbe Y, Delobel B, Sauvion N, Guillaud J, Febvay G (1997) Melon resistance to the aphid Aphis gossypii: Behavioural analysis and chemical correlations with nitrogenous compounds. Entomol Exp Appl 85: 33-44.

Cherqui A, Tjallingii WF (2000) Salivary proteins of aphids, a pilot study on identification, separation and immunolocalisation. J Insect Physiol 46: 1177-1186.

Cristofoletti PT, de Sousa FAM, Terra WR, Rahbe Y (2006) Characterization of a membrane-bound aminopeptidase purified from Acyrthosiphon pisum midgut cells. FEBS J 273: 5574-5588.

de Pinto MC, Tommasi F, De Gara L (2002) Changes in the antioxidant systems as part of the signalling pathway responsible for the programmed cell death activated by nitric oxide and reactive oxygen species in tobacco BY-2 cells. Plant Physiol 130: 698-708.

de Vos M, van Oosten VR, van Poecke RMP, van Pelt JA, Pozo MJ, Mueller MJ, Buchala AJ, Métraux J-P, van Loon LC, Dicke M, et al. (2005) Signal signature and transcriptome changes of Arabidopsis during pathogen and insect attack. Mol Plant-Microbe Interact 18: 923-927.

Decrem Y, Beaufays J, Blasioli V, Lahaye K, Brossard M, Vanhamme L, Godfroid E (2008) A family of putative metalloproteases in the salivary glands of the tick Ixodes ricinus. FEBS J 275: 1485-1499.

Divol F, Vilaine F, Thibivilliers S, Amselem J, Palauqui JC, Kusiak C, Dinant S (2005) Systemic response to aphid infestation by Myzus persicae in the phloem of Apium graveolens. Plant Mol Biol 57: 517-540.

Dixon AFG (1998) Aphid Ecology: An Optimization Approach. Chapman and Hall, London, p 300.

Dogimont C, Chovelon V, Tual S, Boissot N, Rittener V, Giovinazzo N, Bendahmane A (2008) Molecular diversity at the Vat/Pm- $W$ resistance locus in melon. In Pitrat M, ed, Cucurbitaceae 2008. Proceedings of the IXth EUCARPIA meeting on genetics and breeding of Cucurbitaceae. INRA, Avignon, France, pp 219-227.

Ehlers K, Knoblauch M, van Bel AJE (2000) Ultrastructural features of well-preserved and injured sieve elements: Minute clamps keep the phloem transport conduits free for mass flow. Protoplasma 214: 80-92.

Ehrhardt P (1965) Magnesium und Calcium enthaltende Einschlusskorper in den Mitteldarmzellen von Aphiden. Experientia 21: $337-338$.

Eleftherianos I, Vamvatsikos P, Ward D, Gravanis F (2006) Changes in the levels of plant total phenols and free amino acids induced by two cereal aphids and effects on aphid fecundity. J Appl Entomol 130: 15-19.

Evert RF (1990) Dicotyledons. In Behnke H-D, Sjolund RD, eds, Comparative Structure, Induction and Development. Springer, Berlin, pp 103-137.

Fisher DB, Frame JM (1984) A guide to the use of the exuding stylet technique in phloem physiology. Planta 161: 385-393.

Forrest JMS, Noordink JP (1971) Translocation and subsequent uptake by aphids of $\mathrm{P}^{32}$ introduced into plants by radioactive aphids. Entomol Exp Appl 14: 133-134.

Foyer CH, Noctor G (2005) Redox homeostasis and antioxidant signaling: A metabolic interface between stress perception and physiological responses. Plant Cell 17: 1866-1875.

Fujita T, Uchida K, Maruyama N (1992) Purification of senescence marker protein-30 (SMP30) and its androgen-independent decrease with age in the rat liver. Biochim Biophys Acta 1116: 122-128.

Furch ACU, Hafke JB, Schulz A, van Bel AJE (2007) $\mathrm{Ca}^{2+}$-mediated remote control of reversible sieve tube occlusion in Vicia faba. J Exp Bot 58: 2827-2838.

Furch ACU, Zimmermann MR, Will T, Hafke JB, van Bel AJE (2010) Remote-controlled stop of phloem mass flow by biphasic occlusion in Cucurbita maxima. J Exp Bot 61: 3697-3708.

Garzo E, Soria C, Gomez-Guillamon ML, Fereres A (2002) Feeding behavior of Aphis gossypii on resistant accessions of different melon genotypes (Cucumis melo). Phytoparasitica 30: 129-140.

Girousse C, Faucher M, Kleinpeter C, Bonnemain JL (2003) Dissection of the effects of the aphid Acyrthosiphon pisum feeding on assimilate partitioning in Medicago sativa. New Phytol 157: 83-92.

Girousse C, Moulia B, Silk W, Bonnemain JL (2005) Aphid infestation causes different changes in carbon and nitrogen allocation in alfalfa stems as well as different inhibitions of longitudinal and radial expansion. Plant Physiol 137: 1474-1484.

Goggin FL (2007) Plant-aphid interactions: Molecular and ecological perspectives. Curr Opin Plant Biol 10: $399-408$. 
Gould N, Minchin PEH, Thorpe MR (2004) Direct measurements of sieve element hydrostatic pressure reveal strong regulation after pathway blockage. Funct Plant Biol 31: 987-993.

Gould N, Thorpe MR, Koroleva O, Minchin PEH (2005) Phloem hydrostatic pressure relates to solute loading rate: A direct test of the Munch hypothesis. Funct Plant Biol 32: 1019-1026.

Gray S, Gildow FE (2003) Luteovirus-aphid interactions. Annu Rev Phytopathol 41: 539-566.

Harmel N, Letocart E, Cherqui A, Giordanengo P, Mazzucchelli G, Guillonneau F, De Pauw E, Haubruge E, Francis F (2008) Identification of aphid salivary proteins: A proteomic investigation of Myzus persicae. Insect Mol Biol 17: $165-174$.

Hewer A, Will T, van Bel AJE (2010) Plant cues for aphid navigation in vascular tissues. J Exp Biol 213: 4030-4042.

IAGC (2010) Genome sequence of the pea aphid Acyrthosiphon pisum. PLoS Biol 8: e1000313.

Hogenhout SA, van der Hoorn RA, Terauchi R, Kamoun S (2009) Emerging concepts in effector biology of plant-associated organisms. Mol Plant-Microbe Interact 22: 115-122.

Kaloshian I, de Ilarduya OM, Xie QG (2003) Aphid-induced defense responses in Mi-1-mediated compatible and incompatible tomato interactions. Mol Plant-Microbe Interact 16: 699-708.

Kempema LA, Cui XP, Holzer FM, Walling LL (2007) Arabidopsis transcriptome changes in response to phloem-feeding silverleaf whitefly nymphs. Similarities and distinctions in responses to aphids. Plant Physiol 143: 849-865.

Knoblauch M, Noll GA, Muller T, Prufer D, Schneider-Huther I, Scharner D, Van Bel AJE, Peters WS (2003) ATP-independent contractile proteins from plants. Nat Mater 2: 600-603.

Knoblauch M, Peters WS, Ehlers K, van Bel AJE (2001) Reversible calcium-regulated stopcocks in legume sieve tubes. Plant Cell 13: $1221-1230$.

Knoblauch M, van Bel AJE (1998) Sieve tubes in action. Plant Cell 10: 35-50.

Lecourieux D, Ranjeva R, Pugin A (2006) Calcium in plant defence-signalling pathways. New Phytol 171: 249-269.

Leineweber K, Schulz A, Thompson GA (2000) Dynamic transitions in the translocated phloem filament protein. Aust J Plant Physiol 27: 733-741.

Ma R, Chen J, Cheng D, Sun J (2010) Activation of defense mechanism in wheat by polyphenol oxidase from aphid saliva. Agric Food Chem 58: 2410-2418.

Ma R, Reese JC, Black, WC, Bramel-Cox, P (1990) Detection of pectinesterase and polygalacturonase from salivary secretions of living greenbugs, Schizaphis graminum (Homoptera: Aphididae). J Insect Physiol 36: 507-512.

Madhusudhan VV, Miles PW (1998) Mobility of salivary components as a possible reason for differences in the responses of alfalfa to the spotted alfalfa aphid and pea aphid. Entomol Exp Appl 86: 25-39.

Martin B, Collar JL, Tjallingii WF, Fereres A (1997) Intracellular ingestion and salivation by aphids may cause the acquisition and inoculation of non-persistently transmitted plant viruses. J Gen Virol 78: 2701-2705.

Martinez de Ilarduya O, Xie Q-G, Kaloshian I (2003) Aphid-induced defense responses in Mi-1-mediated compatible and incompatible tomato interactions. Mol Plant-Microbe Inter 16: 699-708.

McHale L, Tan XP, Koehl P, Michelmore RW (2006) Plant NBS-LRR proteins: Adaptable guards. Genome Biology 7.

Mclean DL, Kinsey MG (1965) Identification of electrically recorded curve patterns associated with aphid salivation and ingestion. Nature 205: 1130-1131.

McLean DL, Kinsey MG (1984) Precibarial valve and its role in the feeding behavior of the pea aphid, Acyrthosiphon pisum. Bull Entomol Soc Am 30: 26-31.

Miles PW (1999) Aphid saliva. Biol Rev Camb Philos Soc 74: 41-85.

Miles PW, Oertli JJ (1993) The significance of antioxidants in the aphid-plant interaction-the redox hypothesis. Entomol Exp Appl 67: 275-283.

Mittler TE, Sylvester ES (1961) A comparison of the injury of alfalfa by the aphids Therioaphis maculata and Macrosiphum pisi. J Econ Entomol 54: 615-622.

Münch E (1930) Die Stoffbewegung in der Pflanze. Fischer, Jena.

Mutti NS, Louis J, Pappan LK, Pappan K, Begum K, Chen MS, Park Y, Dittmer N, Marshall J, Reese JC, et al. (2008) A protein from the salivary glands of the pea aphid, Acyrthosiphon pisum, is essential in feeding on a host plant. Proc Natl Acad Sci USA 105: 9965-9969.

Mutti NS, Park Y, Reese JC, Reeck GR (2006) RNAi knockdown of a salivary transcript leading to lethality in the pea aphid, Acyrthosiphon pisum. J Insect Science 6: 38.

Noctor G, Queval G (2007) A plate reader method for the measurement of NAD, NADP, glutathione, and ascorbate in tissue extracts: Application to redox profiling during Arabidopsis rosette development. Anal Biochem 363: 58-69.

Pallipparambil GR, Reese JC, Avila CA, Louis JM, Goggin FL (2010) Mi-mediated aphid resistance in tomato: Tissue localization and impact on the feeding behavior of two potato aphid clones with differing levels of virulence. Entomol Exp Appl 135: 295-307.

Pegadaraju V, Knepper C, Reese J, Shah J (2005) Premature leaf senescence modulated by the Arabidopsis PHYTOALEXIN DEFICIENT4 gene is associated with defense against the phloem-feeding green peach aphid. Plant Physiol 139: 1927-1934. 
Peuke AD, Windt C, Van As H (2006) Effects of cold-girdling on flows in the transport phloem in Ricinus communis: Is mass flow inhibited? Plant Cell Environ 29: 15-25.

Ponsen MB (1972) The site of potato leafroll virus multiplication in its vector, Myzus persicae: an anatomical study. Mededeling/Laboratorium voor entomologie, Dissertation 529, p 147.

Potters G, Horemans N, Jansen MAK (2010) The cellular redox state in plant stress biology—a charging concept. Plant Physiol Biochem 48: 292-300.

Powell G, Tosh CR, Hardie J (2006) Host plant selection by aphids: Behavioral, evolutionary, and applied perspectives. Annu Rev Entomol 51: 309-330.

Prado E, Tjallingii WF (1994) Aphid activities during sieve element punctures. Entomol Exp Appl 72: 157-165.

Pyati P, Bandani AR, Fitches E, Gatehouse JA (2011) Protein digestion in cereal aphids (Sitobion avenae) as a target for plant defence by endogenous proteinase inhibitors. J Insect Physiol 57: 881-891.

Queval G, Noctor G (2007) A plate-reader method for the measurement of NAD, NADP, glutathione and ascorbate in tissue extracts. Application to redox profiling during Arabidopsis rosette development. Anal Biochem 363: 58-69.

Rahbé Y, Deraison C, Bonade-Bottino M, Girard C, Nardon C, Jouanin L (2003) Effects of the cysteine protease inhibitor oryzacystatin (OC-I) on different aphids and reduced performance of Myzus persicae on OC-I expressing transgenic oilseed rape. Plant Sci 164: 441-450.

Rahbé Y, Febvay G (1993) Protein toxicity to aphids: an in vitro test on Acyrthosiphon pisum. Entomol Exp Appl 67: 149-160.

Read SM, Northcote DH (1983) Subunit structure and interactions of the phloem proteins of Cucurbita maxima (Pumpkin). Eur J Biochem 134: 561-569.

Sandstrom J (2000) Nutritional quality of phloem sap in relation to host plant-alternation in the bird cherry-oat aphid. Chemoecology 10: 17-24.

Sarria-Villada ES, Gonzalez EG, Lopez-Sese AI, Castiel AF, Gomez-Guillamon ML (2009) Hypersensitive response to Aphis gossypii Glover in melon genotypes carrying the Vat gene. J Exp Bot 60: 3269-3277.

Shimokawa N, Yamaguchi M (1993) Expression of hepatic calcium-binding protein regucalcin mRNA is mediated through $\mathrm{Ca}^{2+} /$ calmodulin in rat liver. FEBS Lett 316: 79-84.

Staal J, Dixelius C (2007) Tracing the ancient origins of plant innate immunity. Trends Plant Sci 12: 334-342.

Suzuki N, Koussevitsky S, Mittler R, Miller G (2012) ROS and redox signalling in the response of plants to abiotic stress. Plant Cell Environ 35: 259-270.

Thompson GA, Leineweber K, Schulz A (2000) Dynamic transitions in the translocated phloem filament protein. Aust J Plant Physiol 27: 733-741.

Tjallingii WF (2006) Salivary secretions by aphids interacting with proteins of phloem wound responses. J Exp Bot 57: 739-745.

Tjallingii WF, Cherqui A (1999) Aphid saliva and aphid plant interactions. Proceedings of the Section Experimental and Applied Entomology. Neth Entomol Soc 10: 169-174.

Tjallingii WF, Esch TH (1993) Fine structure of aphid stylet routes in plant tissues in correlation with EPG signals. Physiol Entomol 18: 317-328.

Urbanska A, Tjallingii WF, Dixon AFG, Leszczynski B (1998) Phenol oxidising enzymes in the grain aphid's saliva. Entomol Exp Appl 86: 197-203.

Urbanska A, Tjallingii WF, Leszczynski B (1994) Application of agarose-sucrose gels for investigation of aphid salivary enzymes. In Aphids and Other Homopterous Insects, Vol. 4. Polish Academy of Science, Skierniewice, Poland, pp 81-87.

van Bel AJE, Hess PH (2008) Hexoses as phloem transport sugars: The end of a dogma? J Exp Bot 59: 261-272.

Van Camp W, Van Montagu M, Inze D (1998) $\mathrm{H}_{2} \mathrm{O}_{2}$ and NO: Redox signals in disease resistance. Trends Plant Sci 3: $330-334$.

van der Westhuizen AJ, Qian XM, Botha AM (1998) Differential induction of apoplastic peroxidase and chitinase activities in susceptible and resistant wheat cultivars by Russian wheat aphid infestation. Plant Cell Rep 18: 132-137.

van Helden M, Tjallingii WF (1993) Tissue localization of lettuce resistance to the aphid Nasonovia ribisnigri using electrical penetration graphs. Entomol Exp Appl 68: 269-278.

van Helden M, Tjallingii WF, Teris A, Vanbeek TA (1994) Phloem sap collection from lettuce (Lactuca sativa L)—chemical comparison among collection methods. J Chem Ecol 20: 3191-3206.

Walker GP (2000) A beginner's guide to electronic monitoring of homopteran probing behavior. In Walker GP, Backus EA, eds, Principles and Applications of Electronic Monitoring and Other Techniques in the Study of Homopteran Feeding Behavior. Thomas Say Publications in Entomology, Entomol Soc Amer, College Park, Maryland, pp 1-40.

Walling LL (2000) The myriad plant responses to herbivores. J Plant Growth Regul 19: 195-216.

Walz C, Juenger M, Schad M, Kehr J (2002) Evidence for the presence and activity of a complete antioxidant defence system in mature sieve tubes. Plant J 31: 189-197.

Wilkinson TL, Douglas AE (1995) Aphid feeding, as influenced by disruption of the symbiotic bacteria—an analysis of the pea aphid (Acyrthosiphon pisum). J Insect Physiol 41: 635-640. 
Will T, Hewer A, van Bel AJE (2008) A novel perfusion system shows that aphid feeding behaviour is altered by decrease of sieve-tube pressure. Entomol Exp Appl 127: 237-245.

Will T, Kornemann SR, Furch ACU, Tjallingii WF, van Bel AJE (2009) Aphid watery saliva counteracts sieve-tube occlusion: A universal phenomenon? J Exp Biol 212: 3305-3312.

Will T, Steckbauer S, Hardt M, van Bel AJE (in press) Aphid gel saliva: sheath structure, protein composition and secretory dependence on stylet-tip milieu. PLoS ONE.

Will T, Tjallingii WF, Thonnessen A, van Bel AJE (2007) Molecular sabotage of plant defense by aphid saliva. Proc Natl Acad Sci USA 104: 10536-10541.

Will T, van Bel AJE (2006) Physical and chemical interactions between aphids and plants. J Exp Bot 57: 729-737.

Wu, J, Baldwin, IT (2010) New insights into plant responses to the attack from insect herbivores. Ann Rev Gen 44: 1-24.

Yamaguchi M (2000) Role of regucalcin in calcium signaling. Life Sci 66: 1769-1780.

Yamaguchi M (2005) Role of regucalcin in maintaining cell homeostasis and function. Int J Mol Med 15: 371-389. 